\title{
SOFRIMENTO PSÍQUICO EM CRIANÇAS E ADOLESCENTES - A BUSCA PELO TRATAMENTO
}

\author{
Psychic suffering in children and adolescents - the search for treatment \\ Sufrimiento psíquico en niños y adolescentes - la búsqueda por tratamiento
}

Ana Ruth Macêdo Monteiro

Kamylla Paulla Saldanha Rabelo ${ }^{4}$
Liane Araújo Teixeira²

Suzane de Fatima do Vale Tavares ${ }^{5}$
Renata Saraiva Martins da Silva ${ }^{3}$

Rafaela Carolini de OliveiraTávora ${ }^{6}$

\section{RESUMO}

Trata-se de uma pesquisa de natureza descritiva com abordagem qualitativa, realizada em um centro de atenção psicossocial infantil - CAPSi, do município de Fortaleza-CE. Este estudo objetiva descrever a atitude da família na busca de tratamento da criança/ adolescente em sofrimento psíquico. Os sujeitos desta pesquisa constituem-se de 42 familiares cuidadores de crianças e adolescentes, usuários do CAPSi. A coleta de dados foi realizada por meio de entrevistas semiestruturadas. A análise dos dados foi feita por meio de entrevistas divididas em categorias, em que as falas com ideias semelhantes se reuniam em uma mesma categoria. Os resultados mostram um importante elemento sobre a falta de assistência à família do indivíduo em adoecimento psíquico, evidenciando a fundamental importância de englobar toda a família no processo terapêutico. Concluiu-se que se fazem necessárias reflexões acerca da atenção de saúde direcionada ao adoecimento psíquico, em relação às crianças e adolescentes, bem como em relação às famílias envolvidas, prevenindo ou intercedendo precocemente no adoecimento psíquico.

Palavras-chave: Saúde mental. Família. Criança. Adolescente. Enfermagem.

\begin{abstract}
This is a research of descriptive nature with a qualitative approach, taken place in a Children's Psychosocial Care Center - CAPSI, in the City of For taleza, Ceará. Forty-two family members who are the caretakers of children and adolescents, CAPSI users, accompanied them through this service on a daily basis. The DATA analysis began, initially, with the detailed and attentive reading and review of the speeches, individually. On the posterior stage, the testimonies were put together in groups, separated by themes in which the speech passages were joined by similar aspects, in which the family relations of the children and adolescents in psychic suffering were identified. The work with the families is a major challenge for the nursing field, since it's in the family context that the affective bonds develop and acknowledging the way these families face their daily situations help the promotion of mental health and prevention of mental illnesses in children and adolescents in psychic distress.
\end{abstract}

Keywords: Mental Health. Family. Child. Adolescents. Nursing.

\section{Resumen}

Se trata de una investigación de naturaleza descriptiva con abordaje cualitativo, realizada en un centro de atención psicosocial infantil - CAPSi, del municipio de Fortaleza-CE. Este estudio tiene como objetivo describir la actitud de la familia en la busca de tratamiento del niño/adolescente con sufrimiento psíquico. Los sujetos de esta investigación son 42 familiares cuidadores de niños y adolescentes, usuarios del CAPSi. La colecta de datos fue realizada por medio de entrevistas semeestructuradas. El análisis de los datos fue hecho a través de entrevistas divididas en categorías, reuniendo las respuestas con ideas semejantes en una misma categoría. Los resultados muestran un importante elemento sobre la falta de asistencia a la familia del individuo en padecimiento psíquico, evidenciando la importancia fundamental de englobar toda la familia en el proceso terapéutico. Se concluye que resulta necesario reflexionar sobre la atención de salud dirigida al padecimiento psíquico, en relación a los niños y adolescentes, así como en relación a las familias implicadas, previniendo o intercediendo precozmente en el padecimiento psíquico.

Palabras-Clave: Salud mental. Familia. Niño. Adolescente. Enfermería.

\footnotetext{
'Enfermeira. Doutora em Enfermagem, docente do Curso de Graduação em Enfermagem e do Curso de Mestrado Acadêmico em Cuidados Clínicos em Saúde da Universidade Estadual do Ceará - UECE, docente da Faculdade Metropolitana de Fortaleza, enfermeira do HM/SUS. Membro do Grupo de Pesquisa em Enfermagem, Educação, Saúde e Sociedade- GRUPEESS. Fortaleza-CE. Brasil. E-mail: anaruthmacedo@yahoo.com.br; ${ }^{2}$ Acadêmica de Enfermagem da Universidade Estadual do Ceará (UECE) do $9^{\circ}$ semestre. Aluna IC/UECE. Membro efetivo do Grupo de Pesquisa em Enfermagem, Educação, Saúde e Sociedade (GRUPEESS). Fortaleza-CE. Brasil. E-mail: lianeteixeiras@hotmail.com; ${ }^{3}$ Acadêmica de Enfermagem da UECE do $9^{\circ}$ semestre. Bolsista PIBIC/UECE. Membro efetivo do Grupo de Pesquisa em Enfermagem, Educação, Saúde e Sociedade (GRUPEESS). Fortaleza-CE. Brasil. E-mail: tatac7s@hotmail.com; ${ }^{4}$ Acadêmica de Enfermagem da UECE do $9{ }^{\circ}$ semestre. Aluna FUNCAP/UECE. Membro efetivo do Grupo de Pesquisa em Enfermagem, Educação, Saúde e Sociedade (GRUPEESS). Fortaleza-CE. Brasil. E-mail: kprabelo@hotmail.com; ${ }^{5}$ Enfermeira. Mestranda em Cuidados Clínicos em Saúde e Enfermagem pela Universidade Estadual do Ceará. Membro efetivo do Grupo de Pesquisa em Enfermagem, Educação, Saúde e Sociedade (GRUPEESS). Fortaleza-CE. Brasil. E-mail: suzane_tavares@hotmail.com; ${ }^{6}$ Enfermeira. Mestranda em Cuidados Clínicos em Saúde e Enfermagem pela Universidade Estadual do Ceará. Especialista em Enfermagem Clínica, Especialista em Gestão de Serviços de Saúde. Membro efetivo do Grupo de Pesquisa em Enfermagem, Educação, Saúde e Sociedade (GRUPEESS). Fortaleza-CE. Brasil. E-mail: rafatavora@yahoo.com.br.
} 


\section{Sofrimento psíquico em crianças e adolescentes}

\section{INTRODUÇÃO}

0 movimento da reforma psiquiátrica surgiu em meados dos anos 80 e introduziu um conjunto de transformações no âmbito social, cultural e político, na busca de uma nova forma de cuidar e conviver com o portador de transtornos psíquicos. Até então, a família do paciente em sofrimento psíquico era excluída do processo terapêutico, devido à política hospitalocêntrica, que desconsiderava o paciente como sujeito e acreditava que a família seria uma influência negativa, o que acabava por enfatizar ainda mais o isolamento e a segregação social desse paciente'.

A família é um sistema importante e de grande influência para a criança e o adolescente em sofrimento psíquico. Ela é o foco central da construção, da transformação, da mudança e do dinamismo, constituindo uma importante instituição formadora e capacitadora dessas crianças e adolescentes. 0 contexto em que essa família se insere influencia nas relações, nas mudanças no seu ciclo de vida, sendo importante considerar o impacto provocado por condições socioeconômicas e culturais. Para tanto, faz-se necessária uma estrutura familiar consistente o bastante para enfrentar as adversidades e conflitos que possam vir a surgir².

Por estar começando a se estruturar como sujeito perante a sociedade, a criança necessita de apoio emocional, social e psicológico, sendo a família a responsável direta por esse suporte.

Já o adolescente, por estar em uma fase de transição entre a vida infantil e a vida adulta, encontra-se em um momento em que muitas escolhas serão feitas. Essas escolhas gerarão grandes transformações, podendo trazer mudanças repentinas no humor, que significaria, por exemplo, passar da tristeza para a raiva ou para a euforia de forma intensa. Nessa fase, a busca incessante por desafios é o que o motiva, sendo o principal destes a aceitação nos grupos sociais que participa ${ }^{3}$.

Quando se trabalha com o sofrimento psíquico em crianças e adolescentes, a família deve ser o foco principal dessa busca por acontecimentos, sentimentos e melhorias, pois esse sofrimento psíquico está interligado intimamente com o contexto familiar em que eles estão inseridos.

Mesmo após a reforma psiquiátrica, a população ainda se encontra em processo de mudança, principalmente na postura em relação ao portador de sofrimento psíquico, dificultada pela pouca informação e pela burocracia na mudança do sistema.

A prevalência de transtornos mentais em crianças e adolescentes tem aumentado significativamente. Quanto maior a faixa etária, proporcionalmente maior será a taxa de prevalência ${ }^{4}$. Por mais que tenha aumentado o número de crianças e adolescentes em adoecimento psíquico, o seu diagnóstico é difícil e por vezes duvidoso. A dificuldade de diagnosticar essa criança e esse adolescente é advinda da forma como esse indivíduo é abordado e julgado pelas pessoas que o circundam.
0 adoecimento psíquico do membro mais jovem da família interfere e modifica a dinâmica familiar, fazendo com que todos os membros se adaptem ou modifiquem seus comportamentos e hábitos, dificultando a relação e inserindo uma carga emocional intensa aos membros.

São muitas as dificuldades enfrentadas pela família que procura ajudar uma criança e um adolescente em sofrimento psíquico: a energia despendida na busca de ajuda; 0 investimento do tempo do familiar; a dependência econômica; a privação das necessidades de outros membros da família; 0 corte das atividades sociais; a diminuição das relações com 0 mundo exterior e as dificuldades em identificar alternativas para hospitalização ou espaços residenciais fora de sua casa ${ }^{5}$.

Tudo isso dificulta a tomada de decisão da família, pois ao mesmo tempo que essa família deseja procurar ajudar o indivíduo em sofrimento psíquico, as dificuldades encontradas nesse percurso fazem com que esta, muitas vezes, desista e acabe por prejudicar ainda mais a vida dessa criança e desse adolescente ${ }^{5}$.

0 familiar se desgasta pela convivência com a pessoa portadora de sofrimento psíquico e passa a sofrer uma sobrecarga física e emocional, privando-se da sua própria vida para poder prestar um cuidado adequado. 0 comportamento imprevisível da pessoa debilita as expectativas sociais e origina incertezas e dificuldades no grupo familiar e na sociedade. Assim, a família acaba por procurar ajuda de terceiros, pois, além de considerar o cuidado com o seu familiar, uma obrigação sua, o amor que o familiar tem por esse indivíduo faz com que tome essa iniciativa ${ }^{6}$.

A família não é concebida nem preparada para cuidar de um indivíduo em sofrimento psíquico. Este se mostra, muitas vezes, como um fardo para quem tem o papel de cuidador, levando-o a buscar ajuda em serviços de saúde. Essa procura pelo serviço de saúde especializado se dá por meio do encaminhamento de outros hospitais ou indicação de terceiros, sendo para essas crianças e adolescentes o início de uma reinserção social, a partir de um cuidado integral, universal e principalmente efetivo.

É nesse momento que a enfermagem começa a atuar, ou seja, no momento que o suporte profissional se mostra necessário tanto para a criança quanto para sua família. Juntamente com a equipe multiprofissional especializada, podese intervir em vários ambientes; neles, a enfermagem mantêm o contato direto com a família, realizando essa intervenção, desde a Estratégia de Saúde da Família até o trabalho mais especializado nos Centros de Atenção Psicossocial InfantoJuvenil (CAPSi).

0 sofrimento psíquico de crianças e adolescentes e 0 envolvimento da família na terapêutica realizada em serviços especializados são uma temática carente na literatura, pois além de ser uma atuação relativamente nova, também existem barreiras na abertura para abordagem de uma população tão vulnerável e com relações tão frágeis. 
Tendo em vista a vivência dos autores no CAPSi de Fortaleza e pela convivência com as dificuldades enfrentadas pelos familiares, surgiu a inquietação em estudar e aprofundar o tema abordado.

Nesse sentido, o presente estudo objetiva descrever a atitude da família na busca de tratamento da criança e do adolescente em sofrimento psíquico.

Ao descrever o que as famílias sentem e quais as dificuldades enfrentadas por elas, pode-se adequar os serviços de acordo com a demanda e intensificar essa nova assistência proposta pela reforma psiquiátrica, sensibilizando os profissionais e a comunidade envolvidos nesse processo.

\section{METODOLOGIA}

Trata-se de um estudo descritivo de natureza qualitativa, pois posiciona o observador no mundo e melhora a apreensão da realidade estudada.

A pesquisa qualitativa é um conjunto de práticas interpretativas e materiais que dão visibilidade ao mundo, transformando-o e fazendo dele uma série de representações, incluindo notas de campo, entrevistas, conversas, fotografias, gravações e anotações pessoais. Essa pesquisa envolve uma postura interpretativa e naturalística do mundo, das coisas em seus contextos naturais, buscando entender ou interpretar os fenômenos em termos dos sentidos que as pessoas thes atribuem? ${ }^{7}$.

Este estudo foi realizado em um Centro de Atenção Psicossocial Infanto-Juvenil (CAPSi), do município de FortalezaCE, no qual estão ativos cerca de 694 prontuários. Nestes, de acordo com os critérios de inclusão, as crianças e adolescentes deveriam ser usuários intensivos e/ou participar de atendimento no CAPSi pelo menos uma vez por semana, por atendimento individual, com psicólogo, terapeuta ocupacional e enfermeiro, e/ou participar de grupos com atividades semanais. Considerando esses critérios, foram selecionados para a pesquisa 99 crianças e adolescentes. Foram excluídos aqueles que tivessem faltado três vezes consecutivas sem justificativa, resultando, assim, em uma amostra de 42 familiares de crianças e adolescentes usuários.

A coleta de dados foi realizada entre os meses de agosto de 2008 a março de 2009, por meio de entrevistas semiestruturadas. As entrevistas foram gravadas e transcritas na íntegra. Após a transcrição das falas, foi realizada a análise dos dados, divididos em categorias.

As entrevistas semiestruturadas referem-se ao fato de que o entrevistado tem um conhecimento individual complexo sobre o tema a ser abordado, sendo incluídas nesse conhecimento suposições explícitas e imediatas, as quais ele pode expressar espontaneamente ao responder a uma pergunta aberta, e que são complementadas por suposições implíitas8.

As transcrições foram analisadas a partir a leitura de cada relato e, a partir delas, foram extraídas e categorizadas temáticas. A categorização é uma forma de análise que pode ser aplicada a todos os tipos de dados e não apresenta um método específico de coleta. A principal atividade é a busca de partes relevantes de dados e sua análise, comparando com outros dados e the dando nomes e classificações. Por esse processo, desenvolve-se uma estrutura nos dados, em direção a uma visão mais abrangente do tema, do campo e dos próprios dados?.

As categorias evidenciadas foram descritas e discutidas, favorecendo um melhor entendimento do fenômeno em estudo, sendo elas: a busca pelo tratamento de crianças e adolescentes em sofrimento psíquico; e as atitudes da mãe na busca pela melhora da criança e do adolescente.

Os entrevistados foram informados que a entrevista seria gravada e foi pedida a assinatura do Termo de Consentimento Livre e Esclarecido a cada um desses cuidadores para que a veracidade das informações fosse preservada, esclarecendo que, a qualquer momento, poderiam sair da pesquisa e que seus nomes seriam preservados.

A entrada em campo para coleta de dados foi precedida de encaminhamento e aprovação do projeto pelo Comitê de Ética em Pesquisa da Universidade Estadual do Ceará, com o protocolo de número 07157886-2, a fim de obter autorização formal para sua execução, obedecendo à Resolução 196/96 do Conselho Nacional de Saúde?.

No momento da coleta de dados, todos os cuidadores foram esclarecidos acerca dos objetivos do estudo, sendo assegurada a eles total liberdade para aceitarem ou não participar da pesquisa, ou abandoná-la em qualquer fase, se assim desejasse. Foi garantido a eles o anonimato na apresentação dos resultados, de maneira que os depoimentos presentes no estudo são identificados por números. Todos os cuidadores assinaram o Termo de Consentimento Livre e Esclarecido.

\section{RESULTADOS E DISCUSSÃO}

A partir das transcrições das entrevistas dos 42 familiares foram obtidos dados acerca da forma de como é realizada a procura de ajuda por familiares de crianças e adolescentes em sofrimento psíquico e os sentimentos expressados por eles com o adoecimento de seu ente querido. Esses dados então foram divididos em duas categorias para a melhor explanação dos temas encontrados.

\section{A busca de ajuda}

A partir da leitura das falas, percebeu-se que existiam duas ideias principais muito recorrentes. A primeira relatava principalmente os motivos que dificultavam a procura da ajuda necessária para esses indivíduos e a segunda ideia relatava a sensação de perigo provocada pela inserção desses indivíduos dentro do lar, da comunidade e da sociedade em geral.

Elencava-se a ideia de que a falta de conhecimento desses familiares dificultava o encaminhamento desses pacientes ao serviço especializado, fazendo com que esses familiares fossem em busca de ajuda na atenção básica. 


\section{Sofrimento psíquico em crianças e adolescentes}

Levei ela para o Gonzaguinha, aía assistente social conversou comigo e disse que ela tinha que ser acompanhada no CAPS. (Entrevista 12)

Eu fui, procurei um médico no Frotinha, e lá me indicaram aqui. (Entrevista 38)

Minha mãe levou no médico pra saber se tinha alguma relação com as convulsões, aí encaminharam pra cá pro CAPS. (Entrevista 41)

Fica evidente que a população não tem conhecimento dos serviços prestados por entidades de saúde mental, como o CAPS ou hospitais-dia, ou até mesmo os hospitais mentais, nem sobre o seu papel na procura de melhorias para pessoas com sofrimento psíquico.

0 Programa Saúde da Família (PSF) deveria ser um articulador entre a rede de saúde mental e a população, desenvolvendo atividades que incluíssem a prevenção e a promoção de saúde mental. No entanto, a falta de sensibilização dos profissionais dificulta essa articulação e a efetivação dessas ações de saúde, que deveriam lidar com os determinantes sociais do adoecimento, realizar práticas intersetoriais e desenvolver o exercício da cidadania ${ }^{10}$.

Os familiares, na maioria das vezes, percebem que 0 comportamento da criança ou adolescente mudou, sendo considerado anormal e estranho. Há a percepção de que estão com problemas e a partir desse estranhamento é que se inicia a busca por tratamento.

...só que eu achei que ele ia melhorar... eu levei no médico depois de grande e fui tentar, e consegui depois de três anos no posto e estou aqui fazendo o tratamento dele. (Entrevista 22)

fui vendo que ele tinha algum problema... aí fui pra doutora." (Entrevista 35)

(...) eu liguei para minha mãe "ela não está bem não, venha aqui em casa", quando minha mãe viu, ligou para o meu tio aí informaram aqui o Caps, eu trouxe aqui. (Entrevista 40)

Eu achei que ela não estava boa, foi daí que eu comecei a procurar um tratamento pra ela. Eu fui primeiro no Albert Sabin, mas muito difíici...muito difícil...quase uma semana procurando ver se conseguia essa consulta. (Entrevista 43)

0 adoecimento psíquico é facilmente percebido porque, em geral, os indivíduos neste estado apresentam comportamento fora do padrão de normalidade, diferente do que apresentavam anteriormente. Além disso, frequentemente esse comportamento é inaceitável para a sociedade ${ }^{11}$.

Esse adoecer não é bem esclarecido para a comunidade, tendo uma definição mais cultural e de valores do que de fatores biológicos propriamente ditos. A loucura é estigmatizada e não permite que o indivíduo adoecido tenha acesso à sua cidadania, sendo segregado e excluído da sociedade ${ }^{11}$.

A acessibilidade ao serviço especializado ainda é muito difícil devido a vários fatores, tais como: a sobrecarga desses serviços, a dificuldade de acesso direto e a barreira criada pelos serviços de atenção básica que, por muitas vezes, não estão preparados para diagnosticar e encaminhar esses pacientes ao serviço de saúde mental.

Já consegui um encaminhamento pra trazer ela pra cá, para fazer o tratamento. (Entrevista 02)

.Eu já tinha tentado, fiquei numa fila de espera e não conseguimos, começamos em particular, mas estava ficando muito pesado, aí, quando foi um dia que eu precisava ir na regional, resolver um problema, me indicaram aqui. Depois que eu vim pra cá... (Entrevista 25)

Porque eu andava de médico em médico com ele, e os médicos diziam que era normal, normal. Um dia ele teve uma crise, uma convulsão, aíme indicaram o Caps, até hoje eu estou aqui com ele. (Entrevista 26)

Eu levei ele num psiquiátrica, ele disse que não era com ele. Tive que procurar um outro acompanhamento, tive que ir pro Caps infantil. Aí eu vim pra cá, foi quando eu recebi ajuda... (Entrevista 36)

Meu paifoi procurar pelo Brasil todinho profissionais que possam cuidar dele, mas não encontrou, só encontrou aqui em Fortaleza. Aí ele trouxe aqui pro CAPS. (Entrevista 39)

De acordo com os cuidadores, o encaminhamento ao CAPS se dá de formas distintas e confusas, o que demonstra a falta de conhecimento da população sobre a existência e o papel do CAPS na sociedade. Além da falta de informativos e propagandas que popularizem os cuidados prestados pelo CAPS, de acordo com os cuidadores, os próprios profissionais da área também dificultam o caminho entre usuário e serviço.

De concreto, sabe-se que não há serviços na comunidade suficientes e disponíveis que consigam dar conta da demanda de portadores de transtorno mental e seus familiares com efetividade. Sabe-se, também, que a ocorrência de uma doença grave e de longa duração, como a doença mental, ativa uma 
série de respostas nas pessoas de seu grupo social, especialmente entre aquelas do convívio familiar ${ }^{12}$.

0 enfermeiro insere-se nessa procura por meio do acolhimento no CAPSi, da criação de vínculo, além da participação na terapêutica, realizando a escuta em consultas, grupos ou visita domiciliar. Esse enfermeiro tem papel de orientar e assistir a família do usuário em sofrimento psíquico, visando abranger a família como um todo, na busca de minimizar o sofrimento da criança ou adolescente e de seus entes ${ }^{13}$.

A segunda ideia principal que envolve as falas dos familiares é a de que a criança ou adolescente representa perigo para as pessoas em volta, sendo motivo de dificuldade e sobrecarga para essas famílias que não estão habituadas a lidar com comportamentos alterados e estranhos. Assim, a doença torna-se um grande fardo para todos em volta, principalmente para os cuidadores, que não são preparados para lidar com tanta responsabilidade.

Procurei o CAPSi pra dar um jeito de internar ou qualquer coisa, porque a gente não está mais suportando. (Entrevista 08)

Aí eu pedi ajuda né? Eencontrei porque não dava não... (Entrevista 10)

Ele chegou no abrigo, teve um atrito familiar, a própria mãe chamou o ronda. (Entrevista 1)

A convivência com o transtorno mental implica uma sobrecarga caracterizada por dificuldades como: problemas no relacionamento com o familiar, estresse por conviverem com o humor instável e a dependência do portador de sofrimento psíquico, bem como o medo das recaídas e do comportamento deste no período das crises $^{14}$.

Nesse sentido, o cuidador é descrito como um indivíduo adulto relacionado a outro pelo parentesco ou por afetividade, sem quaisquer benefícios, que assume responsabilidade pela pessoa portadora de sofrimento psíquico.

A pessoa cuidada é aquela que necessita de um acompanhamento devido a sua dificuldade ou incapacidade de desempenhar funções cotidianas e normativas ao indivíduo dentro da sociedade, requerendo cuidados devido à condição de sofrimento vivida, constituindo-se sobrecarga para o familiar que necessita assumir papel adicional de cuidador, além do papel já assumido na família.

Pode-se perceber que a falta de acessibilidade, 0 preconceito e a desinformação da população são grandes obstáculos para que haja um tratamento de forma digna e eficaz para essa criança ou adolescente. Faz-se necessária a mudança desse pensamento retrógrado e preconceituoso de quem teoricamente não tem sofrimento psíquico, pois a sua falta de humanidade e sensibilidade faz com que o desenvolvimento do sistema direcionado para a saúde mental não aconteça.
A regressão do sofrimento psíquico e a inserção social dos usuários não está ligada somente à terapêutica formal no CAPSi, a interação social e as relações dentro da comunidade podem oferecer experiências positivas em relação à melhora do quadro ${ }^{15}$.

A partir desse posicionamento de que o jovem tem que ser inserido na comunidade, o enfermeiro que atua em conjunto com as crianças e adolescentes deve estimular a criação de novas relações, a abertura de novos convívios dos usuários fora do CAPSi, podendo também orientar a família e favorecer a conscientização da importância das atividades no cotidiano do usuário, sejam elas atividades de lazer, domésticas ou até mesmo algum trabalho.

\section{Atitudes da mãe na busca pela melhora da criança ou adolescente}

A partir das falas das mães pode-se desvendar os sentimentos e as atitudes tomadas por elas na busca pela melhora da criança ou adolescente. Descobriu-se que existiam somente dois intensos sentimentos produzidos por estas mães e que estes influenciavam em suas atitudes.

0 primeiro sentimento é o amor incondicional que sentem pelos filhos, o que faz com que elas não temam 0 sofrimento, o preconceito e as dificuldades que serão enfrentadas. Somente estas mães que vivenciam essa experiência indescritível sabem o pesar desse cargo.,

Mesmo assim tem que apoiar, dar carinho, dar atenção e acompanhar ela direto para o CAPSi... (Entrevista 01)

Agora eu dou amor, eu dou carinho pra ela, ela me beija, eu beijo ela, de manhã eu acordo ela, ela merenda, vai pra escola, eu vou levar ela, vou buscar, venho trazer ela aqui para o CAPSi, faço de tudo. (Entrevista 07)

Se eu puder fazer tudo por ele eu faço, só não vou matar e nem roubar, mas o que eu puder fazer por ele, porque ele foi o meu primeiro filho. (Entrevista 10)

Eu acho que não tem nenhuma mãe pra fazer igual a mim não. Se ele disser: mãe eu quero isso, eu já faço um jeito de comprar. (Entrevista 11)

Eu tento ser a melhor mãe do mundo pra ele, daro que eu posso pra ele (Entrevista 24)

Agora eu tenho lutado muito, batalho muito com ele, vou à luta, mas ele é forte, é resistente, é agressivo. (Entrevista 29) 


\section{Sofrimento psíquico em crianças e adolescentes}

Eu tento ser o mais amiga possível, procuro conversar, procuro saber se ele está com algum problema, conversar. (Entrevista 32)

Diante do impacto do adoecimento, as possibilidades de trocas afetivas que, de fato, sejam verdadeiras, ficam reduzidas. Há uma imposição aos familiares de uma vivência de sentimentos e emoções que são difíceis de elaborar e entender. Isso evidencia a necessidade de intervenção que acolha o sofrimento apresentado, considerando a subjetividade e individualidade das pessoas ${ }^{14}$.

Mesmo para essas mães com amor tão intenso, a dificuldade por elas enfrentada faz com que muitas vezes se sintam desamparadas e frágeis. Por mais que o sentimento de amor seja grande, o pesar de obter um ser totalmente dependente faz com e essas crianças ou adolescentes representem um grande fardo a ser carregado por elas.

0 segundo sentimento expressado por essas mães é 0 de dever, obrigação, pois quando a criança, ou o adolescente, necessita de cuidados especiais essas mães se sentem frustradas por não terem sido capazes de gerar um filho dentro do padrão de normalidade, sobrecarregando-as e dificultando o seu desempenho como responsável.

É, tem que cuidar, porque a gente não pode deixar ela do jeito que está né? Ela tem que ter o tratamento rígido. (Entrevista 02)

Porque antes eu só pensava em ir embora e deixar ele, e agora eu penso em cuidar dele pra ele melhorar. (Entrevista 23)

Às vezes eu perco a paciência, mas eu trato ele melhor, eu não bato nele, quando ele vem me gritar, falo pra ele baixar a voz, que sou uma pessoa de idade que sou vó dele, sou mãe dele. (Entrevista 28)

Com o envolvimento da família no tratamento do portador de transtorno mental, mas com suporte a ela para enfrentar as dificuldades no relacionamento com a loucura e a sobrecarga, a carga emocional da família e do próprio usuário é amenizada, aumentando o nível de interação e empatia entre eles $^{14}$.

Visto que o serviço especializado para crianças ou adolescentes em sofrimento psíquico já apresenta um déficit entre a oferta de serviço e a demanda de pacientes, deve-se também ter atenção com a saúde mental da família envolvida no processo, pois ela é a entidade-chave no atual tipo de terapêutica, sendo responsável por promover o contato entre 0 doente e os serviços de saúde existentes.

Por ser um membro da equipe multiprofissional que está em constante contato com o usuário em tratamento, 0 enfermeiro pode estar direcionando o seu cuidado também à família da criança e do adolescente assistido, além de inserilos na terapêutica do jovem, como forma de enriquecer os cuidados a serem realizados com a criança e 0 adolescente em sofrimento psíquico.

Com a contribuição dos relatos desses familiares acerca das dificuldades em procurar os serviços de saúde mental, podemos melhorar a qualidade do serviço prestado pelo enfermeiro, tanto na rede básica, onde o enfermeiro pode estar realizando um cuidado inespecífico, porém eficaz até as suas limitações, quanto no CAPSi, no qual o enfermeiro pode prestar um cuidado específico, dando suporte tanto para a criança e o adolescente em sofrimento psíquico como para a sua família.

Essa visão dos familiares da falta de informação e de sistematização no direcionamento da assistência mostra-nos a relevância do trabalho que o enfermeiro pode realizar em educação em saúde e de informar a comunidade em geral acerca dos agravos que podem surgir em relação à saúde mental.

Esse estudo mostra como, apesar de todo o movimento da reforma psiquiátrica, ainda existe muita desinformação dentro da comunidade em si, dos profissionais e do próprio sistema, dificultando o alcance desses jovens em sofrimento psíquico à terapêutica adequada, além de ainda não oferecer o suporte adequado aos familiares do usuário, que sofrem junto com seu ente.

A realidade aqui exposta só demonstra os sentimentos de alguns cuidadores de uma população bastante específica; não podemos generalizar os aspectos vividos por eles e suas contribuições para a atuação no serviço, pois cada serviço apresenta características e problemáticas diferentes, limitando a nossa contribuição a esse tipo de dificuldade encontrada no sistema.

\section{CONSIDERAÇÕES FINAIS}

A família representa o meio em que o indivíduo deve estar em segurança, por esta fazer parte do cuidado e da manutenção da terapêutica ministrada, além de ser o meio onde a criança ou adolescente se estrutura e aprende a se relacionar na sociedade, delimitando-se como sujeito de acordo com a conformaç̧ão familiar.

Os cuidadores ocupam um papel de fundamental importância na reabilitação e reinserção dessas crianças ou adolescentes em sofrimento psíquico na sociedade. Por esse grande espaço ocupado por eles, deve-se estar atento em envolvê-los na terapêutica aplicada aos usuários, pois, apesar de muitas vezes não demonstrarem algum sofrimento psíquico, as influências desse novo estilo de vida são capazes de interferir na saúde mental deles e da família toda, em um âmbito geral.

Devido à convivência e aos conflitos gerados por esses cuidados prestados, torna-se evidente a importância de englobar toda a família no processo terapêutico, fazendo com que esse cuidado seja individualizado, pois cada membro da família tem um grau de participação diferente. 
A família que procura tratamento para a criança ou adolescente em sofrimento psíquico encontra algumas dificuldades, tanto pela falta de informação da própria família, que se direciona a hospitais gerais na busca de tratamento, como pela falta de sensibilização dos profissionais que recebem essa família, que dificultam o acesso a serviços especializados ou até mesmo nem direcionam essa família a esses serviços.

Mesmo na atenção básica, que deveria ser a porta de entrada do usuário a serviços mais especializados como o CAPSi, os familiares encontram dificuldades, pois os profissionais não direcionam e nem atuam na terapêutica das crianças ou adolescentes de forma adequada, de forma a limitar e empobrecer a reinserção e melhora desses jovens.

Quando a família consegue acesso ao serviço especializado, este ainda não se faz suficiente, pois essa família também necessita de cuidados e o CAPSi ainda é carente nessa terapêutica mais ampliada, o que dificulta o processo terapêutico das crianças e adolescentes.

Apesar de já existirem algumas mudanças devido à reforma psiquiátrica, ainda existem muitas a serem efetivadas, devendo-se enfatizar o cuidado especializado da criança ou adolescente que, além de não suprir a demanda, ainda não tem meios exatos de ministrar terapêuticas que sejam de acordo com cada tipo de adoecimento mental.

É de suma importância unir os profissionais da área de saúde mental para aprofundar os estudos a respeito da assistência utilizada atualmente e da eficácia de seus resultados. A partir desses estudos é que serão criadas novas terapias que trabalhem com a criança ou adolescente como um sujeito, levando-se em consideração que esse sujeito ainda está em formação física e mental.

\section{REFERÊNCIAS}

1.Mello R. A construção do cuidado à família e a consolidação da reforma psiquiátrica. Rev Enferm UERJ. 2005; 13: 390-95.

2.Macêdo VCD, Monteiro ARM. Educação e saúde mental na família: experiência com grupos vivenciais. Texto\&Contexto Enferm. 2006 abr/ jun; 15(2): 222-30.

3.Crivelatti MMB, Durman S, Hofstatter LM. Sofrimento psíquico na adolescência. Texto\&Contexto Enferm. 2006; 15 (n esp): 64-70.

4.Assumpção Junior FB. A questão da psicopatologia na infância e na adolescência; aspectos práticos. Infância, sofrimento emocional e clínica contemporânea. Anais da $4^{\mathrm{a}}$ Jornada APOIAR - Infância, sofrimento emocional e a clínica contemporânea;2006. 1; São Paulo, Brasil. São Paulo: IP/USP; 2006. p. 11-39.

5.Hirdes A, Kantorski LP. A família como um recurso central no processo de reabilitação psicossocial. Rev Enferm UERJ. 2005; 13(2): 160-66.
6.Navarini V, Hirdes A. A família do portador de transtorno mental: identificando recursos adaptativos. Texto\&Contexto Enferm. 2008 out/ dez; 17(4): 680-88.

7.Flick U. Análise dos dados qualitativos. In: Flick U. Desenho da pesquisa qualitativa. Porto Alegre: Artmed, 2009.

8.Flick U. Entrevistas semi-estruturadas. In: Flick U. Uma introdução à pesquisa qualitativa. Porto Alegre: Artmed; 2004.

9.Ministério da Saúde(BR). Conselho Nacional de Saúde.. Resolução nº196, de 10 de outubro de 1996. Diretrizes e normas regulamentadoras de pesquisas envolvendo seres humanos. Brasília(DF); 1997.

10.Nunes M, Jucá VJ, Valentim CPB. Ações de saúde mental no Programa Saúde da Família: confluências e dissonâncias das práticas com os princípios das reformas psiquiátrica e sanitária. Cad Saude Publica. 2007 out; 23(10): 2375-84.

11.Spadini LS, Souza MCBM. A doença mental sob o olhar de pacientes e familiares. Rev Esc Enferm USP. 2006; 40(1): 123-27.

12.Colvero LA, Ide CAC, Rolim MA. Família e doença mental: a difícil convivência com a diferença. Rev Esc Enferm USP. 2004 fev; 38(2): 197 205.

13.Dias CB, Aranha e Silva AL. 0 perfil e a ação profissional da(o) enfermeira(o) no Centro de Atenção Psicossocial. Rev Esc Enferm USP. 2010; 44(2): 469-475.

14.Borba LO, Schwartz E, Kantorski LD. A sobrecarga da família que convive com a realidade do transtorno mental. Acta Paul Enferm. 2008 jul; 21(4): 588-94.

15.Falavina OP, Cerqueira MB. Saúde mental infanto-juvenil: usuários e suas trajetórias de acesso aos serviços de saúde. Rev Espaço para a Saúde. 2008; 10(1): 34-46. 